\title{
Phase I-II Trial of Foscarnet for Prevention of Cytomegalovirus Infection in Autologous and Allogeneic Marrow Transplant Recipients
}

\author{
Pierre Reusser, John G. Gambertoglio, Kathy Lilleby, \\ and Joel D. Meyers*
}

\author{
Fred Hutchinson Cancer Research Center, Seattle. Washington; Division \\ of Clinical Pharmacy, University of California. San Francisco
}

\begin{abstract}
The safety and efficacy of foscarnet for prevention of cytomegalovirus (CMV) infection was evaluated in $19 \mathrm{CMV}$-seropositive bone marrow transplant (BMT) recipients. All patients received intermittent intravenous (iv) foscarnet: $40 \mathrm{mg} / \mathrm{kg}$ every $8 \mathrm{~h}$ from 7 days before to day 30 after BMT, then $60 \mathrm{mg} / \mathrm{kg}$ once a day until day 75 . The main toxicity was transient renal dysfunction, with $\mathrm{a}>50 \mu \mathrm{mol} / \mathrm{L}$ increase in serum creatinine above baseline in 5 of the 7 autograft recipients and in 6 of the 12 allograft recipients. Only 4 allograft recipients developed CMV infection during foscarnet prophylaxis, and no patient showed evidence of CMV disease. Because 3 allograft recipients receiving concomitant iv amphotericin B showed rapid impairment of renal function, foscarnet prophylaxis should not be given to allograft recipients requiring amphotericin B; otherwise, foscarnet prophylaxis at this dose appears safe after BMT.
\end{abstract}

Infection due to cytomegalovirus (CMV) causes significant morbidity and mortality among bone marrow transplant (BMT) recipients [1]. In two published series, the probability of CMV infection within the first 100 days after BMT among patients who were CMV-seropositive before transplant was up to $80 \%$ and $60 \%$ for allograft and autograft recipients, respectively $[2,3]$. Mortality was primarily related to CMV pneumonia, which developed in $37 \%$ of allograft and in $22 \%$ of autograft recipients who had evidence of active CMV infection [2, 3]. Thus, the prevention of CMV infection and disease after BMT is of foremost importance.

Antiviral chemotherapy aimed at preventing reactivation of latent virus may be the most promising approach to $\mathrm{CMV}$ prophylaxis both among CMV-seropositive autograft and allograft recipients and among seronegative allograft recipients who have a seropositive marrow donor. CMV drug prophylaxis should cover the early period after BMT in which a deficiency in $\mathrm{CMV}$-specific immunity can contribute to the risk of severe CMV disease [4].

The antiviral agent acyclovir given intravenously at high doses was shown to be partially effective in preventing CMV infection and disease among seropositive BMT recipients [5].

Received 3 January 1992: revised 16 March 1992.

Presented in part: 3rd International Cytomegalovirus Workshop, Bologna, Italy, June 1991 (abstract 130).

All patients or their parents or guardians gave informed consent. Human experimentation guidelines of the US Department of Health and Human Services were followed, and the study protocol was approved by the institutional review board of Fred Hutchinson Cancer Research Center and the US Food and Drug Administration.

Financial support: Swiss National Research Foundation and Swiss Cancer League (to P.R.); National Institutes of Health (CA-18029, CA-1 5704, HL36444).

Reprints or correspondence (present address): Dr. Pierre Reusser, Department of Medicine, University Hospital, $\mathrm{CH}-403$ ! Basel, Switzerland.

* Deceased

The Journal of Infectious Diseases 1992;166:473-9 (C) 1992 by The University of Chicago. All rights reserved. $0022-1899 / 92 / 6603-0002 \$ 01.00$
Ganciclovir, which is more active than acyclovir against CMV [6], was evaluated in two recent prospective randomized controlled trials among BMT recipients $[7,8]$. In these two studies of early treatment with ganciclovir in patients who had engrafted (increased neutrophil count after BMT) and who developed CMV excretion, the incidence of subsequent CMV disease was significantly reduced, but severe neutropenia occurred in 30\%-35\% of treated patients [7, 8].

The antiviral drug foscarnet (trisodium phosphonoformate) inhibits herpesvirus DNA polymerase activity $[9,10]$ and was shown to suppress replication of both laboratory strains and clinical isolates of CMV in vitro [11-13]. Clinical studies among transplant recipients and patients with AIDS who received foscarnet treatment for severe CMV disease have shown therapeutic effects and indicate that renal dysfunction is the main adverse experience associated with foscarnet, whereas neutrophil counts do not appear to be substantially affected [14]. Foscarnet could prove as efficient as ganciclovir in preventing CMV disease in BMT recipients but could be less toxic to the bone marrow and could therefore be used as CMV prophylaxis starting before BMT. In view of emerging resistance of CMV to ganciclovir [15-18], foscarnet also could be used as an alternative prophylactic regimen if resistance to ganciclovir is documented.

We report a prospective phase I-II trial of intermittent intravenous foscarnet for the prevention of $\mathrm{CMV}$ infection and disease among CMV-seropositive autologous and allogeneic BMT recipients. Except for one pilot trial in which 10 $\mathrm{CMV}$-seropositive marrow recipients were given continuous intravenous administration of foscarnet for prophylaxis [19], no data on prophylactic regimens using foscarnet among BMT recipients have yet been published.

\section{Patients and Methods}

Patients admitted over a 10 -month period to Fred Hutchinson Cancer Research Center or Swedish Hospital Medical Center in 
Seattle were selected for study if they underwent autologous or allogeneic BMT for hematologic malignancy and if they were CMV-seropositive before transplant. Exclusion criteria were age $<12$ years, a known allergy to foscarnet, ongoing treatment with acyclovir or ganciclovir, graft-versus-host disease (GVHD) prophylactic regimen other than cyclosporine plus methotrexate among allograft recipients $[20]$, proven $\mathrm{CMV}$ disease before transplant, or renal insufficiency (serum creatinine $>133 \mu \mathrm{mol}$ / L) at the time of initiation of foscarnet prophylaxis. Patients who underwent a second marrow transplant or who received a $\mathrm{T}$ cell-depleted marrow graft were also excluded.

The methods of pretransplant conditioning and posttransplant care have been described [21, 22]. Allogeneic transplant recipients were given cyclosporine plus a short course of methotrexate as GVHD prophylaxis [20]. No patient received intravenous immune globulins for prevention of infections or GVHD. Since every patient was CMV-seropositive, blood products transfused during the study period were not screened for CMV.

Protocol design. Because the main adverse effect of foscarnet is renal dysfunction [14], foscarnet was first evaluated in autograft recipients. Autograft recipients do not receive cyclosporine, which has known nephrotoxic potential [23]. Once foscarnet proved safe in autograft recipients, the drug was administered to allogeneic marrow recipients.

Foscarnet sodium solution (Astra Clinical Associates, Hopkinton, MA) was supplied in $500-\mathrm{mL}$ glass bottles at $24 \mathrm{mg} / \mathrm{mL}$ in an isotonic solution with $\mathrm{HCl}$ to adjust $\mathrm{pH}$ to 7.4. Each dose was administered through a central venous line by using an infusion pump. Two regimens of foscarnet were evaluated. The inpatient regimen was a $1-\mathrm{h}$ infusion of foscarnet at $40 \mathrm{mg} / \mathrm{kg}$ every $8 \mathrm{~h}$ beginning 7 days before BMT and continuing to day 30 after BMT or until discharge from hospital if earlier. The calculated total daily dose of $120 \mathrm{mg} / \mathrm{kg}$ corresponds to twothirds of the dosage (180 mg/kg/day) used as induction treatment for CMV retinitis in patients with AIDS [24, 25]. The outpatient regimen was a $1-h$ intravenous infusion of foscarnet daily at a dose of $60 \mathrm{mg} / \mathrm{kg}$ given until day 75 after BMT.

Because foscarnet is eliminated by renal excretion [14], the dosage was adjusted when the calculated creatinine clearance was $<1.4 \mathrm{~mL} / \mathrm{min} / \mathrm{kg}$. Continuous adjustments were made until clearance dropped to $<0.4 \mathrm{~mL} / \mathrm{min} / \mathrm{kg}$, at which time treatment was stopped. Patients who developed CMV disease were eligible for available therapy protocols, and participation in the foscarnet trial was terminated. If treatment of herpes simplex virus or varicella-zoster virus infection required acyclovir therapy, foscarnet treatment was interrupted and resumed on discontinuation of acyclovir therapy.

Phase I-safety. To assess potential drug toxicity, the following data were recorded daily for inpatients and at least three times a week for outpatients: white blood cell (WBC) counts with differential counts, hemoglobin level, platelet counts, and serum creatinine level. Serum calcium, magnesium, and phosphorus concentrations were obtained and liver function tests were done three times a week. Any clinical symptoms or signs possibly related to foscarnet treatment were recorded daily. The rapidity of engraftment during foscarnet treatment was evaluated by determining the number of days required for patients to reach WBC counts of $1.0 \times 10^{9} / \mathrm{L}$, absolute neutrophil counts of
$0.5 \times 10^{9} / \mathrm{L}$, or platelet counts of $20 \times 10^{9} / \mathrm{L}$ and $50 \times 10^{9} / \mathrm{L}$ on 2 consecutive days not sustained by platelet transfusions.

Phase II-efficacy. Viral cultures were prepared from throat, urine, and blood specimens from each patient before treatment and weekly during and after treatment for a minimum of 100 days after transplant. Viral cultures from other sites or from tissue specimens were prepared when clinically indicated. The clinical specimens were inoculated onto monolayers of human foreskin fibroblasts and observed for up to 5 weeks. Positive cultures were identified by the appearance of typical cytopathic effects, and, in the case of equivocal results, further identification was done by indirect immunofluorescence with murine monoclonal antibodies (Syva, Palo Alto, CA). Serum samples obtained weekly were tested for IgG antibody to CMV by ELISA (CMV Stat; Whittaker M.A. Bioproducts, Walkersville, $\mathrm{MD}$ ).

CMV infection was defined as excretion of the virus or presence of CMV in tissue specimens but without clinical symptoms. CMV disease was defined as presence of CMV in tissue specimens or in bronchoalveolar lavage (BAL) fluid with associated clinical symptoms and signs.

Pharmacokinetics of foscarnet. Blood specimens were obtained from each patient for pharmacokinetic studies at steady state after 1 week of foscarnet treatment and at weekly intervals thereafter. Blood $(2 \mathrm{~mL})$ was drawn immediately before and at the end of a given foscarnet infusion and again before the next consecutive infusion of the drug. Foscarnet plasma levels were determined by high-performance liquid chromatography with electrochemical detection as described [26]. The lowest concentration of foscarnet detectable by this assay is $33 \mu \mathrm{mol} / \mathrm{L}$. Calculation of plasma half-lives $\left(t_{1 / 2}\right)$ of foscarnet was done as described [27].

\section{Results}

The clinical characteristics of the 19 patients enrolled in the study are summarized in table 1 . Duration of foscarnet prophylaxis, median daily dose, and reasons for premature discontinuation are in table 2 .

\section{Safety of Foscarnet}

Renal function. The main toxicity associated with foscarnet prophylaxis was impaired renal function (table 3 ). Of the 7 autograft recipients, $6(86 \%)$ developed renal toxicity, with an increase in serum creatinine above baseline of $>50 \mu \mathrm{mol} /$ $L$ in 5 patients $(71 \%)$. In 2 of these 5 patients, impairment was severe enough to require termination of foscarnet (after 18 and 8 days of foscarnet treatment) and hemodialysis.

Of the 2 requiring hemodialysis, 1 patient had acute toxicity consisting of diffuse skin rash, hypotension, and renal failure (peak serum creatinine, $733 \mu \mathrm{mol} / \mathrm{L}$ ). This patient had been receiving concomitant treatment with granulocytemacrophage colony-stimulating factor and intravenous amphotericin B, which could have contributed to toxicity. Both foscarnet and amphotericin B were discontinued (on day 10 
Table 1. Characteristics of marrow transplant recipients receiving foscarnet.

\begin{tabular}{|c|c|c|}
\hline & $\begin{array}{l}\text { Autograft } \\
\text { recipients }\end{array}$ & $\begin{array}{l}\text { Allograft } \\
\text { recipients }\end{array}$ \\
\hline No. of patients & 7 & 12 \\
\hline Median age, years (range) & $25(14-60)$ & $31.5(12-59)$ \\
\hline Sex, male/female & $6 / 1$ & $9 / 3$ \\
\hline \multicolumn{3}{|l|}{ Underlying disease } \\
\hline Acute nonlymphoblastic leukemia & 4 & 1 \\
\hline Acute lymphoblastic leukemia & 0 & 3 \\
\hline Chronic myeloid leukemia & 0 & 7 \\
\hline Non-Hodgkin's lymphoma & 3 & 0 \\
\hline Hodgkin's disease & 0 & 1 \\
\hline \multicolumn{3}{|l|}{ Conditioning regimen } \\
\hline Cy + FTBI & $5^{*}$ & 7 \\
\hline $\mathrm{Bu}+\mathrm{Cy}$ & 1 & 3 \\
\hline $\mathrm{VP} 16+\mathrm{BCNU}+\mathrm{Cy}$ & 1 & 2 \\
\hline \multicolumn{3}{|l|}{ Type of allogeneic transplant } \\
\hline \multicolumn{3}{|l|}{ Related donor } \\
\hline HLA-matched & & 9 \\
\hline HLA-mismatched & & 1 \\
\hline \multicolumn{3}{|l|}{ Unrelated donor } \\
\hline HLA matched & & 2 \\
\hline
\end{tabular}

NOTE. Cy, cyclophosphamide; FTBI, fractionated total body irradiation: Bu, busulfan; VP16, etoposide; BCNU, carmustine.

* Includes I patient who also recejved busulfan for conditioning.

after BMT), and renal function was eventually restored. The second patient showed an immediate reaction on the day of the marrow infusion that was attributed to dimethyl sulfoxide used for cryopreservation of bone marrow. Although serum creatinine was $71 \mu \mathrm{mol} / \mathrm{L}$ when foscarnet was stopped (on the day of BMT), creatinine levels rose to a peak of 804 $\mu \mathrm{mol} / \mathrm{L}$ in this patient, with recovery to $141 \mu \mathrm{mol} / \mathrm{L}$ by day 37 after BMT. Whether renal failure in this patient was related to foscarnet treatment could not be determined.

The remaining 4 autograft recipients who showed renal

Table 2. Duration and dosage of foscarnet treatment in marrow transplant recipients for prevention of cytomegalovirus infection.

\begin{tabular}{|c|c|c|}
\hline & $\begin{array}{l}\text { Autograft } \\
\text { recipients } \\
(n=7)\end{array}$ & $\begin{array}{c}\text { Allograft } \\
\text { recipients } \\
(n=12)\end{array}$ \\
\hline $\begin{array}{l}\text { Time on foscarnet in days, } \\
\text { median (range) }\end{array}$ & $32(8-83)$ & $34.5(10-83)$ \\
\hline \multicolumn{3}{|c|}{ Daily dose in $\mathrm{mg} / \mathrm{kg}$, median (range) } \\
\hline Inpatient regimen & $112(73-120)$ & $116(56-120)$ \\
\hline Outpatient regimen & $60(32-60)$ & $56(32-60)$ \\
\hline $\begin{array}{l}\text { No. of patients with prematu } \\
\text { discontinuation of } \\
\text { foscarnet treatment }(\%)\end{array}$ & $5(71)^{*}$ & $7(58)^{\dagger}$ \\
\hline
\end{tabular}

* 2 related to rena! toxicity; ! died of idiopathic interstitial pneumonia after 32 days of treatment: I died of cardiac toxicity related to chemotherapy after 26 days of treatment; 1 had leukemic relapse after 44 days of treatment.

$\dagger 3$ related to renal toxicity; 3 required intravenous amphotericin $B$ therapy: 1 required acyclovir for oral herpes simplex virus infection.
Table 3. Toxicity during foscarnet treatment in marrow transplant recipients for prevention of cytomegalovirus infection.

\begin{tabular}{lcc}
\hline Adverse experience & $\begin{array}{c}\text { Autograft } \\
\text { recipients } \\
(n=7)\end{array}$ & $\begin{array}{c}\text { Allograft } \\
\text { recipients } \\
(n=12)\end{array}$ \\
\hline $\begin{array}{l}\text { Renal insufficiency } \\
\text { Serum creatinine increase above }\end{array}$ & & \\
$\quad$ baseline & $6(86)$ & $11(92)$ \\
$\quad$ Creatinine increase $>50 \mu$ mol/L & $5(71)$ & $6(50)$ \\
Requiring premature discontinuation & & \\
$\quad$ of drug & $2(29)$ & $3(25)$ \\
$\quad$ Requiring hemodialysis & $2(29)$ & $2(17)$ \\
Electrolyte abnormalities & & $10(83)$ \\
Hypocalcemia & $6(86)$ & $12(100)$ \\
Hypophosphatemia & $5(71)$ & $3(25)$ \\
Hypomagnesemia & $1(14)$ & $1(8)$ \\
Hypermagnesemia & 0 & $5(42)$ \\
Liver failure & $2(29)$ & $3(25)$ \\
Other disorders & & 0 \\
$\quad$ Skin rash & & \\
Paresthesia & $1(71)$ & \\
Nausea/vomiting & $1(14)$ & 0 \\
\hline
\end{tabular}

NOTE. Data are no. (\%).

toxicity had transient increases in serum creatinine that did not necessitate discontinuation of foscarnet. All 4 received concomitant intravenous amphotericin B treatment for a median of 10.5 days (range, 2-22). The one autograft recipient who showed no reduction of renal function also received concomitant intravenous amphotericin B treatment for 28 days.

Of the 12 allograft recipients, 11 (92\%) developed increases in serum creatinine above baseline that were $>50$ $\mu \mathrm{mol} / \mathrm{L}$ in $6(50 \%)$. Three allograft recipients showed rapid impairment of renal function requiring premature discontinuation of foscarnet after 16,17, and 19 days of treatment. Two of the 3 required hemodialysis. One of the dialysed patients did not improve and died on day 40 after BMT (32 days after foscarnet was stopped) from gram-negative sepsis, GVHD, and multiorgan failure. Renal function in the other 2 patients normalized within 10 and 14 days after discontinuation of foscarnet. These 2 patients had received intravenous amphotericin $B$ during the 3 days before foscarnet treatment was stopped. An additional allograft recipient who was given foscarnet and concomitant amphotericin B developed a rapid increase in serum creatinine (peak, $283 \mu \mathrm{mol} / \mathrm{L}$ ), which did not necessitate premature withdrawal from the study but which required temporary discontinuation of foscarnet for 8 days. On the basis of the experience in these 3 patients, concomitant use of foscarnet and intravenous amphotericin $B$ in allograft recipients also receiving cyclosporine was subsequently precluded.

Electrolytes. Hypocalcemia and hypophosphatemia were frequent after initiation of foscarnet treatment (table 3). No patient showed clinical symptoms or signs attributable to 
Table 4. Hematologic monitoring before and during foscarnet treatment in marrow transplant recipients for prevention of cytomegalovirus infection.

Autograft recipients Allograft recipients

\begin{tabular}{|c|c|c|}
\hline \multirow{2}{*}{\multicolumn{3}{|c|}{ Hemoglobin level }} \\
\hline & & \\
\hline Before treatment, $\mathrm{g} / \mathrm{dL}$ & $12.3(11.0-16.9)$ & $11.2(8.7-14.3)$ \\
\hline $\begin{array}{l}\text { Minimum level during } \\
\text { treatment, } \mathrm{g} / \mathrm{dL}\end{array}$ & $9.5(9.1-10.2)$ & $9.2(6.8-10.9)$ \\
\hline Time to minimum, days & $13(2-35)$ & $15(5-75)$ \\
\hline No. of $\mathrm{RBC}$ transfusions & & \\
\hline per patient & $16(4-18)$ & $14(7-30)$ \\
\hline \multicolumn{3}{|l|}{ WBC } \\
\hline Before treatment, $\times 10^{9} / \mathrm{L}$ & $7.6(2.6-14.7)$ & $9.1(1.0-23.2)$ \\
\hline $\begin{array}{l}\text { Time to counts } \geqslant 1.0 \text { after } \\
\text { transplant, days }\end{array}$ & $13(12-27)$ & $18(11-23)$ \\
\hline \multicolumn{3}{|l|}{ Neutrophil counts } \\
\hline Before treatment, $\times 10^{9} / \mathrm{L}$ & $5.6(2.1-10.1)$ & $4.9(0.6-13.5)$ \\
\hline $\begin{array}{l}\text { Time to counts } \geqslant 0.5 \text { after } \\
\text { transplant, days }\end{array}$ & $17(14-27)$ & $17(11-23)$ \\
\hline \multicolumn{3}{|l|}{ Platelet counts } \\
\hline Before transplant, $\times 10^{9} / \mathrm{L}$ & $199(87-372)$ & $194(17-2400)$ \\
\hline $\begin{array}{l}\text { Time to counts } \geqslant 20 \text { after } \\
\text { transplant, days* }\end{array}$ & $56(56->75)$ & $22(15->75)$ \\
\hline $\begin{array}{l}\text { Time to counts } \geqslant 50 \text { after } \\
\text { transplant, days* }\end{array}$ & $64(64->75)$ & $24(15->75)$ \\
\hline
\end{tabular}

NOTE. RBC, red blood cells; WBC, white blood cells. Data are median (range).

* Patients who died before reaching specific cell count while on foscarnet treatment were excluded.

$\dagger$ Counts maintained on at least 2 consecutive days without platelet transfusion support.

changes in serum calcium, magnesium, or phosphorus levels, but all were supplemented by intravenous infusions when serum levels were low.

Liver function. Seven patients had liver failure, defined as total serum bilirubin $>85 \mu \mathrm{mol} / \mathrm{L}$, aspartate aminotransferase $>200$ units/L, or both (table 3 ). All cases appeared to be unrelated to foscarnet use. The decision to terminate foscarnet during the study was never based on liver toxicity.

Hematologic effects. The results of hematologic monitoring before and during foscarnet treatment are shown in table 4. Hemoglobin levels dropped during treatment for all autograft recipients and for $10(83 \%)$ of 12 allograft recipients, reaching a minimum at a median of 13 and 15 days, respectively, after initiation of foscarnet, which corresponded to the end of the first week after BMT. The median number of red blood cell transfusions per patient was similar when the 7 patients who completed a full course of foscarnet prophylaxis were compared with the entire study population ( $16 \mathrm{vs}$. 14 units). No patient had foscarnet discontinued because of hematologic toxicity.

\section{Efficacy of Foscarnet}

The virologic results obtained during and after foscarnet treatment are shown in table 5. Autograft recipients had no evidence of CMV infection while on foscarnet prophylaxis. One autograft recipient had a BAL for pulmonary infiltrates after 16 days of foscarnet treatment that was negative for CMV. Two (29\%) of the 7 autograft recipients had CMV recovered from urine specimens 31 and 67 days after foscarnet was stopped. No other viruses were isolated in autologous BMT recipients.

CMV infection occurred in 4 (33\%) of the 12 allograft recipients during foscarnet treatment. Two were receiving the inpatient regimen and 2 the outpatient regimen. In 4 additional patients (33\%), CMV infection developed a median of 36 days (range, 24-52) after the drug was discontinued. CMV disease did not develop in any allograft recipient during foscarnet prophylaxis. However, 2 allograft recipients (17\%) developed BAL-proven CMV pneumonia 37 and 42 days after foscarnet was stopped, and both died.

Herpes simplex virus infection was documented in 4 allograft recipients (33\%) during foscarnet treatment and in 2 (17\%) after the end of treatment. One allograft recipient (8\%) had adenovirus recovered from the throat and from urine 48 days after discontinuation of foscarnet.

Table 5. Virologic results during and after foscarnet treatment in marrow transplant recipients for prevention of cytomegalovirus (CMV) infection.

\begin{tabular}{|c|c|c|c|c|}
\hline \multirow[b]{2}{*}{$\begin{array}{l}\text { Virus, culture } \\
\text { site }\end{array}$} & \multicolumn{2}{|c|}{$\begin{array}{l}\text { During foscarnet } \\
\text { treatment }\end{array}$} & \multicolumn{2}{|c|}{$\begin{array}{c}\text { After foscarnet } \\
\text { treatment }\end{array}$} \\
\hline & $\begin{array}{l}\text { No. of } \\
\text { patients } \\
\text { culture- } \\
\text { positive }\end{array}$ & $\begin{array}{c}\text { Day of } \\
\text { treatment }\end{array}$ & $\begin{array}{l}\text { No. of } \\
\text { patients } \\
\text { culture- } \\
\text { positive }\end{array}$ & $\begin{array}{l}\text { Days after } \\
\text { end of } \\
\text { treatment }\end{array}$ \\
\hline \multicolumn{5}{|c|}{ Autograft recipients } \\
\hline \multicolumn{5}{|c|}{ CMV } \\
\hline Throat & 0 & & 0 & \multirow{3}{*}{31,67} \\
\hline Urine & 0 & & 2 & \\
\hline Blood & 0 & & 0 & \\
\hline BAL & $0 / 1$ & 16 & & \\
\hline \multicolumn{5}{|c|}{ Allograft recipients } \\
\hline \multicolumn{5}{|c|}{ CMV } \\
\hline Throat & 1 & \multirow[t]{2}{*}{11} & $5^{*}$ & $1,5,35,39,59$ \\
\hline Urine & 0 & & $5^{*}$ & $1,10,24,52,56$ \\
\hline Blood & 3 & $22.67,77$ & 2 & 36,82 \\
\hline BAL & & & $2 / 2$ & 37,42 \\
\hline \multicolumn{5}{|c|}{ Herpes simplex virus } \\
\hline Throat & 4 & $17,25,44,46$ & 2 & 2,69 \\
\hline \multicolumn{5}{|l|}{ Adenovirus } \\
\hline Throat & 0 & & 1 & 48 \\
\hline Urine & 0 & & 1 & 48 \\
\hline
\end{tabular}

NOTE. BAL, bronchoalveolar lavage. If patient had multiple cultures from same site positive for specific virus. only first culture result is reported. If patient had positive cultures from different sites, results from each site are reported once.

* Two patients with CMV viremia during foscarnet treatment began to excrete CMV from throat and urine after completion of foscarnet prophylaxis. 
Table 6. Peak and trough foscarnet plasma levels at steady state during intermittent intravenous (iv) treatment in marrow transplant recipients for prevention of cytomegalovirus infection.

\begin{tabular}{|c|c|c|c|c|}
\hline \multirow{2}{*}{$\begin{array}{l}\text { Creatinine } \\
\text { clearance } \\
(\mathrm{mL} / \mathrm{min} / \mathrm{kg})\end{array}$} & \multicolumn{2}{|c|}{ Autograft recipients } & \multicolumn{2}{|c|}{ Allograft recipients } \\
\hline & Peak & Trough & Peak & Trough \\
\hline \multicolumn{5}{|c|}{ Inpatient regimen* } \\
\hline$\geqslant 1.4$ & $256(86-405)$ & $<33(<33-40)$ & $264(134-780)$ & $44(<33-228)$ \\
\hline $0.4-1.3$ & $288(156-547)$ & $48(<33-153)$ & $315(186-588)$ & $170(<33-568)$ \\
\hline \multicolumn{5}{|c|}{ Outpatient regimen ${ }^{\dagger}$} \\
\hline$\geqslant 1.4$ & $306(177-332)$ & $<33^{\ddagger}$ & $387(52-895)$ & $<33(<33-108)$ \\
\hline $0.4-1.3$ & $377(283-382)$ & $<33(<33-243)$ & $279(<33-313)$ & $<33^{\ddagger}$ \\
\hline
\end{tabular}

NOTE. Data are median (range) values in $\mu \mathrm{mol} / \mathrm{L}$.

* $40 \mathrm{mg} / \mathrm{kg}$ every $8 \mathrm{~h}$ infused iv over $1 \mathrm{~h}$.

$\dagger 60 \mathrm{mg} / \mathrm{kg} /$ day infused iv over $\mathrm{I} \mathrm{h}$.

All values $<33 \mu \mathrm{mol} / \mathrm{L}$ (detection limit of assay).

\section{Pharmacokinetics of Foscarnet}

Table 6 shows the steady-state peak and trough plasma levels of foscarnet during the inpatient and outpatient regimens at full doses and at reduced doses when the creatinine clearance was $0.4-1.3 \mathrm{~mL} / \mathrm{min} / \mathrm{kg}$. Complete data were available for calculations of plasma $t_{1 / 2}$ of foscarnet in 3 autograft and 9 allograft recipients. During the inpatient regimen, median plasma $t_{1 / 2}$ of foscarnet was $2.9 \mathrm{~h}$ (range, 2.1-8.4) among autograft recipients and $6.2 \mathrm{~h}$ (range, 1.6-15.9) among allograft recipients. Because most trough plasma levels were below the limit of detectability during the outpatient foscarnet regimen (table 6 ), plasma $t_{1 / 2}$ could be determined in only 1 allograft recipient and was $6 \mathrm{~h}$. There was no correlation between the magnitude of plasma $t_{1 / 2}$ of foscarnet and the occurrence of $\mathrm{CMV}$ infection.

\section{Discussion}

The most serious toxicity associated with foscarnet prophylaxis in our patients was impaired renal function. An increase in serum creatinine of $>50 \mu \mathrm{mol} / \mathrm{L}$ above baseline levels was observed in $11(58 \%)$ of the 19 patients during foscarnet treatment. Renal insufficiency led to premature withdrawal from the study of 5 patients (26\%). The relationship of renal insufficiency to foscarnet use was considered possible in 4 of these 5 patients and was judged unevaluatable in the other. The frequency and severity of renal toxicity in our study was in the range of that in other studies of allogeneic BMT recipients and AIDS patients [24, 25, 28-32].

Among our allograft recipients, who all received cyclosporine, it rapidly became clear that foscarnet and amphotericin B could not be used simultaneously without development of renal insufficiency. Subsequently, foscarnet was discontinued whenever intravenous amphotericin B was needed in a patient receiving cyclosporine. However, foscar- net could be used safely with amphotericin B among autograft recipients who do not receive cyclosporine.

A recent study suggests that renal toxicity associated with the use of foscarnet can be prevented by hydration with intravenous isotonic saline given daily during treatment [32]. In that study, only 1 (4\%) of 27 patients with AIDS and CMV retinitis who received foscarnet with hydration developed acute renal failure. Peak serum creatinine levels in this group of patients were significantly lower than in a historical control group that had received the same foscarnet regimen without hydration [32]. Reduction of renal toxicity would allow a larger proportion of BMT recipients to receive a full course of foscarnet prophylaxis, which may reduce the incidence of CMV infection after transplant.

Abnormalities of serum electrolytes were common but not associated with clinical symptoms or signs, suggesting they were minor adverse effects of foscarnet prophylaxis. Clinical manifestations may have been prevented by intravenous replacement of these compounds when required. In a study of 10 AIDS patients, abnormalities of serum calcium and phosphorus levels were observed in 9 cases but were not accompanied by symptoms and normalized after foscarnet induction treatment was completed [24]. After BMT, the causes of hypocalcemia, hypophosphatemia, or hypomagnesemia are probably multifactorial. Thus, the contribution of foscarnet to these conditions in our study remains unclear.

A decrease in hemoglobin levels was frequently observed in this study and was most common early after BMT. However, the requirements of red blood cell transfusions among patients who received a full course of foscarnet prophylaxis did not exceed those reported in earlier studies from our transplant center among both allograft and autograft recipients who did not receive foscarnet $[33,34]$. The rapidity of engraftment after BMT was also similar to that among autologous and allogeneic BMT recipients who were not treated with foscarnet $[3,35]$. Premature discontinuation of foscarnet prophylaxis was not based on hematologic toxicity in any 
patient. In contrast, studies of ganciclovir in BMT recipients have reported severe neutropenia that required dose modifcations or discontinuation of the drug in $30 \%-35 \%$ of patients $[7,8]$.

CMV infection was prevented in all of our autograft recipients but occurred in $33 \%$ of allograft recipients during treatment. No patient in this study showed evidence of CMV disease while receiving foscarnet prophylaxis. These results compare favorably with those from an earlier pilot study in which $50 \%$ of CMV-seropositive allogeneic BMT recipients receiving continuous infusions of prophylactic foscarnet developed CMV infection [19]. Peak plasma levels obtained with intermittent infusion of the drug in our study were more than double the levels measured with continuous infusion of foscarnet in that previous trial, which may explain the improved efficacy.

With one exception [17], earlier studies of foscarnet among BMT recipients used continuous intravenous infusions to administer the drug $[13,19,28,29,36-38]$. In one of these studies that reported data on pharmacokinetics [29], the steady-state serum levels of foscarnet in 13 allogeneic BMT recipients who received a daily dose of foscarnet similar to the dose in our inpatient regimen were $273 \pm 43 \mu \mathrm{mol} /$ $\mathrm{L}$ (mean $\pm \mathrm{SE}$ ). In our study, the median peak plasma concentrations of foscarnet obtained during the inpatient and outpatient regimens among autograft and allograft recipients ranged from 256 to $387 \mu \mathrm{mol} / \mathrm{L}$. The trough plasma levels of foscarnet, however, were usually $<33 \mu \mathrm{mol} / \mathrm{L}$, the detection limit of the assay [26]. Most clinical isolates of CMV are inhibited at concentrations of foscarnet of $200-400 \mu \mathrm{mol} / \mathrm{L}$ in in vitro cell cultures $[14,18]$. Our results indicate that continuously elevated plasma concentrations of foscarnet do not appear to be necessary to prevent CMV infection in BMT recipients.

Prevention of CMV infection and disease appeared effective only while patients were actively taking the drug. After discontinuation of foscarnet, CMV infection occurred in 2 autograft (29\%) and 4 allograft recipients (33\%), and CMV pneumonia developed in 2 allogeneic BMT recipients (17\%). However, except for 1 allograft recipient who had CMV excretion in the throat and urine after a full course of foscarnet prophylaxis, all of these patients were prematurely withdrawn from the study and did not receive alternative antiviral prophylaxis (data not shown). It remains conjectural whether a full course of foscarnet treatment or the replacement of foscarnet by drugs such as acyclovir [5] or ganciclovir $[7,8]$ might have altered the course.

Our data suggest that intermittent intravenous foscarnet prophylaxis is effective in preventing CMV disease among patients who tolerate the full course of treatment. However, foscarnet should not be given to allogeneic BMT recipients receiving cyclosporine who require intravenous amphoteri- cin B. With that exception, prophylaxis at the doses used appears to be safe after both autologous and allogeneic BMT.

\section{Acknowledgments}

We thank M. Wieckowicz for editorial review and M. Marti and $M$. Spörri for assistance in manuscript preparation.

\section{References}

1. Reusser P. Cytomegalovirus infection and disease following bone marrow transplantation: epidemiology, prevention, and treatment. Bone Marrow Transplant 1991;7(suppl 3):52-6.

2. Meyers JD, Ljungman P, Fisher LD. Cytomegalovirus excretion as a predictor of cytomegalovirus disease after marrow transplantation: importance of cytomegalovirus viremia. J Infect Dis 1990;162:37380.

3. Reusser P, Fisher LD, Buckner CD, Thomas ED, Meyers JD, Cytomegalovirus infection after autologous bone marrow transplantation: occurrence of cytomegalovirus disease and effect on engraftment. Blood 1990; 75:1888-94.

4. Reusser P, Riddell SR, Meyers JD, Greenberg PD. Cytotoxic T lymphocyte response to cytomegalovirus following human allogeneic bone marrow transplantation: pattern of recovery and correlation with cytomegalovirus infection and disease. Blood 1991;78:137380 .

5. Meyers JD, Reed EC, Shepp DH, et al. Acyclovir for prevention of cytomegalovirus infection and disease after allogeneic marrow transplantation. N Engl J Med 1988;318:70-5.

6. Balfour HH Jr. Management of cytomegalovirus disease with antiviral drugs. Rev Infect Dis 1990; 12(suppl 7):\$849-60.

7. Schmidt GM, Horak DA, Niland JC, et al. A randomized, controlled trial of prophylactic ganciclovir for cytomegalovirus pulmonary infection in recipients of allogeneic bone marrow transplants. $\mathrm{N}$ Engl $\mathbf{J}$ Med 1991;324:1005-11.

8. Goodrich JM, Mori M, Gleaves CA, et al. Prevention of cytomegalovirus disease after allogeneic marrow transplantation by early treatment with ganciclovir. N Engl J Med 1991;325:1601-7.

9. Helgstrand E, Eriksson B, Johansson NG, et al. Trisodium phosphonoformate, a new antiviral compound. Science 1978;201:819-21.

10. Reno JM, Lee LF. Boezi JA. Inhibition of herpesvirus replication and herpesvirus-induced deoxyribonucleic acid polymerase by phosphonoformate. Antimicrob Agents Chemother 1978;1 3:188-92.

11. Wahren B, Öberg B. Reversible inhibition of cytomegalovirus replication by phosphonoformate. Intervirology 1980;14:7-15.

12. Eriksson B, Öberg B, Wahren B. Pyrophosphate analogues as inhibitors of DNA polymerases of cytomegalovirus, herpes simplex virus and cellular origin. Biochim Biophys Acta 1982;696:1 15-23.

13. Akesson-Johansson A, Lernestedt JO, Ringdén $O$, Lönnqvist $B$, Wahren B. Sensitivity of cytomegalovirus to intravenous foscarnet treatment. Bone Marrow Transplant 1986;1:215-20.

14. Öberg B. Antiviral effects of phosphonoformate (PFA. foscarnet sodium). Pharmacol Ther 1989;40:2 13-85.

15. Erice A, Chou S, Biron KK, Stanat SC, Balfour HH Jr, Jordan MC Progressive disease due to ganciclovir-resistant cytomegalovirus in immunocompromised patients. N Engl J Med 1989;320:289-93.

16. Drew WL, Miner RC, Busch DF, et al. Prevalence of resistance in patients receiving ganciclovir for serious cytomegalovirus infection. J Infect Dis 1991;163:716-9.

17. Drobyski WR, Knox KK, Carrigan DR, Ash RC. Foscarnet therapy of 
ganciclovir-resistant cytomegalovirus in marrow transplantation. Transplantation 1991;52:155-7.

18. Biron KK. Ganciclovir-resistant human cytomegalovirus clinical isolates; resistance mechanisms and in vitro susceptibility to antiviral agents. Transplant Proc 1991;23(suppl 3): 162-7.

19. Ringdén O, Lönnqvist B, Aschan J, Sundberg B. Foscarnet prophylaxis in marrow transplant recipients [letter]. Bone Marrow Transplant 1989;4:713.

20. Storb R, Deeg HJ, Pepe M, et al. Methotrexate and cyclosporine versus cyclosporine alone for prophylaxis of graft-versus-host disease in patients given HLA-identical marrow grafts for leukemia: long-term follow-up of a controlled trial. Blood 1989;73:1729-34.

21. Thomas ED, Storb R, Clift RA, et al. Bone marrow transplantation. $N$ Engl J Med 1975;292:832-43, 895-902.

22. Petersen FB, Appelbaum FR, Hill R, et al. Autologous marrow transplantation for malignant lymphoma: a report of 101 cases from Seattle. J Clin Oncol 1990;8:638-47.

23. Kennedy MS, Deeg HJ, Siegel M, Crowley JJ, Storb R, Thomas ED. Acute renal toxicity with combined use of amphotericin B and cyclosporine after marrow transplantation. Transplantation 1983;35: $211-5$

24. Jacobson MA, O'Donnell JJ, Mills J. Foscarnet teatment of cytomegalovirus retinitis in patients with the acquired immunodeficiency syndrome. Antimicrob Agents Chemother 1989;33:736-41.

25. Studies of Ocular Complications of AIDS Research Group, in collaboration with the AIDS Clinical Trials Group. Mortality in patients with the acquired immunodeficiency syndrome treated with either foscarnet or ganciclovir for cytomegalovirus retinitis. N Engl J Med 1992;326:213-20.

26. Hassanzadeh MK, Aweeka FT, Wu S, Jacobson MA, Gambertoglio JG. Determination of phosphonoformic acid in human plasma and urine by high-performance liquid chromatography with electrochemical detection. J Chromatogr 1990;525:133-40.

27. Aweeka F, Gambertoglio J, Mills J, Jacobson MA. Pharmacokinetics of intermittently administered intravenous foscarnet in the treatment of acquired immunodeficiency syndrome patients with serious cytomegalovirus retinitis. Antimicrob Agents Chemother 1989;33:742-5.

28. Klintmalm G, Lönnqvist B, Öberg B, et al. Intravenous foscarnet for the treatment of severe cytomegalovirus infection in allograft recipients. Scand $J$ Infect Dis 1985; 17:157-63.

29. Ringdén O, Lönnqvist B, Paulin T, et al. Pharmacokinetics, safety and preliminary clinical experiences using foscarnet in the treatment of cytomegalovirus infections in bone marrow and renal transplant recipients. J Antimicrob Chemother 1986;17:373-87.

30. Walmsley SL, Chew E, Read SE, et al. Treatment of cytomegalovirus retinitis with trisodium phosphonoformate hexahydrate (foscarnet) J Infect Dis 1988;157:569-72.

31. Jacobson MA, Crowe S, Levy J, et al. Effect of foscarnet therapy on infection with human immunodeficiency virus in patients with AIDS. J Infect Dis 1988;1 58:862-5.

32. Deray G, Martinez F, Katlama C, et al. Foscarnet nephrotoxicity: mechanism, incidence and prevention. Am I Nephrol 1989;9:316-21.

33. Bowden RA, Sayers M, Gleaves CA, Banaji M, Newton B, Meyers JD. Cytomegalovirus-seronegative blood components for the prevention of primary cytomegalovirus infection after marrow transplantation. Considerations for blood banks. Transfusion 1987;27:478-81.

34. Bowden RA, Slichter SJ, Sayers MH, Mori M, Cays MJ, Meyers JD. Use of leukocyte-depleted platelets and cytomegalovirus-seronegative red blood cells for prevention of primary cytomegalovirus infection after marrow transplant. Blood 1991;78:246-50.

35. Atkinson K. Reconstruction of the haemopoietic and immune systems after marrow transplantation. Bone Marrow Transplant 1990; 5:209-26.

36. Apperley JF, Marcus RE, Goldman JM, Wardle DG, Gravett PJ, Chanas A. Foscarnet for cytomegalovirus pneumonitis [letter]. Lancet $1985 ; 1: 1151$.

37. Ringdén $O$, Wilczek $H$, Lönnqvist B, Gahrton $G$, Wahren B, Lernestedt JO. Foscarnet for cytomegalovirus infections [letter]. Lancet $1985 ; 1: 1503-4$.

38. Ganly PS, Arthur JM, Goldman JM, Schulenburg WE. Foscarnet as treatment for cytomegalovirus retinitis following bone marrow transplantation. Postgrad Med J 1988;64:389-91. 